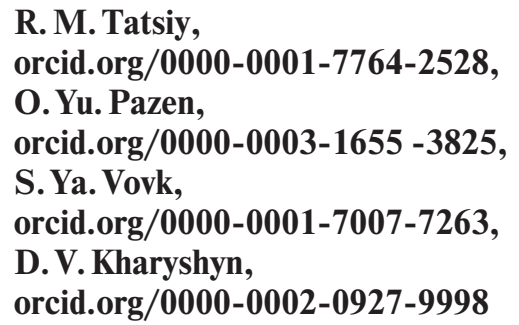

\title{
DIRECT METHOD OF STUDYING HEAT EXCHANGE IN MULTILAYERED BODIES OF BASIC GEOMETRIC FORMS WITH IMPERFECT HEAT CONTACT
}

Purpose. Characteristics of heat transfer processes in multilayer bodies of basic geometric shapes simultaneously under conditions of convective heat transfer on its surfaces and taking into account imperfect thermal contact between the layers.

Methodology. A direct method was applied to solve a one-parameter family of boundary value problems in the theory of heat conduction. This method is based on the reduction method, the concept of quasiderivatives, a system of differential equations with impulse action, the method of separation of variables, and the modified method of eigenfunctions of Fourier. It is worth noting that the application of the concept of quasiderivatives allows you to circumvent the well-known problem of multiplication of generalized functions, which arises when using the differentiation procedure of the coefficients of a differential equation. Such a procedure, in our opinion, casts doubt on the equivalence of the transition to the differential equation obtained in this way with generalized coefficients.

Findings. The solution to the problem is obtained in a closed form. The proposed algorithm does not contain a solution to volume conjugation problems. It includes only: a) finding the roots of the corresponding characteristic equations; b) the multiplication of a finite number of known $(2 \times 2)$ matrices; c) the calculation of certain integrals; d) summing the required number of members of the series to obtain the specified accuracy. As an illustration, we consider model examples of heating eight-layer structures in a fire.

Originality. For the first time, the direct method has been applied to solving the problem of the distribution of an unsteady temperature field over the thickness of multilayer structures of basic geometric shapes simultaneously, in the presence of imperfect thermal contact between the layers.

Practical value. The implementation of the research results allows us to effectively study the heat transfer processes in multilayer structures, which are found in a number of applied problems.

Keywords: heat exchange, body shape coefficient, imperfect thermal contact

Introduction. From a practical point of view, heat transfer problems are almost always accompanied by the solution of one or even several related problems. They are used in the study on the strength of parts and machines, the study on thermal stress of the body, during friction and wear, strengthening of structural elements or individual parts [1-3]. The combination of solutions to individual problems solves problems encountered in the civil, automotive, shipbuilding, aerospace, biomedical, energy, chemical, nuclear, and microelectronics industries, including the design and development of buildings, pipelines, heat exchangers, and more.

Numerous works are devoted to the study of the problem of heat transfer in multilayer structures. In them, as a rule, boundary value problems are solved for multilayer bodies of a specific canonical form. The vast majority of them are limited to the case of ideal thermal contact between the layers. However, in our opinion, the problems of thermal conductivity of multilayer structures taking into account the imperfect thermal contact are insufficiently studied. The article proposes the application of a new analytical solution to the study on heat transfer in multilayer bodies of basic geometric shapes simultaneously, by solving a one-parameter family of certain boundary value problems.

Literature review. In his work, Yang, X.J [4, 5] proposes a new approach that combines a variable-iterative method and an integral transformation that is similar to the Fourier transform. Jiang, J., and Zhou, J. in [6] propose an analytical solution of the Laplace equation for layered media in a cylindrical domain under general boundary conditions. In [7], a method for calculating thermal fields for multilayer beams with an arbitrary location of the heat source was developed, which in-

(C) Tatsiy R. M., Pazen O. Yu., Vovk S. Ya., Kharyshyn D. V., 2021 cludes a method for separating variables. Similar problems are solved by the method of Green's functions in [8]. Solutions for the Laplace equation are presented for layered media in a cylindrical domain under general boundary conditions. They are obtained by the method of separation of variables using SturmLiouville theory and Bessel functions and are presented in [9].

After analyzing the differential equations of thermal conductivity for three coordinate systems (flat, cylindrical, and spherical ones), it was found that we can make a general statement of the problem by introducing into the equation some parameter, which is called the coefficient of body shape [10]. This idea is not new. It has already been realized in the works of Eliseev V. N. and Tovstonoga V.A. for the case of stationary thermal conductivity [10] and non-stationary [11]. This approach was independently used by the authors and implemented to find the solution of the differential equation of thermal conductivity under conditions of ideal thermal contact in [12].

The above-cited works concern only the equations of thermal conductivity under conditions of ideal thermal contact between layers. The number of studies with conditions of imperfect thermal contact is quite limited. For example, in [13] the solution of the axisymmetric contact problem of thermoelasticity is constructed about the pressure of a circular cylindrical isotropic stamp on an elastic isotropic half-space taking into account the imperfect thermal contact through a thin intermediate layer between the stamp and the half-space. In [14], mathematical modeling of the conditions of non-ideal thermal contact of layers due to fine inclusion with heat sources was performed. In [15], an axisymmetric temperature problem was solved for a system of two contacting layers taking into account non-ideal thermal contact.

Numerous methods are becoming increasingly popular due to the advancement of computer technology. From a practical 
point of view, analytical solutions can be quite cumbersome and complex, but they have a number of advantages over numerical ones: they give more accurate results; lead to a better understanding of the research process through its mathematical form; moreover, they can be used to verify numerical codes [12]

Unsolved aspects of the problem. In the works cited above, the authors are usually limited to two layers [16]. This is due to the fact that the increase in the number of layers (given the choice of methods of practical implementation) leads to certain computational difficulties. Therefore, the problem of constructing an effective analytical scheme for the study on heat transfer processes in multilayer structures in the presence of imperfect thermal contact between the layers remains an urgent task. The scheme proposed in the work allows, in any case, avoiding the procedure of finding the originals, which is the most difficult stage in the implementation of various operational methods $[4,6,14,15]$.

Problem statement and its mathematical model. Multilayer structures (flat, cylindrical, and spherical shapes simultaneously) are considered, the area of which is limited by surfaces $r$ $=r_{0}$ and $r=r_{n}$. This region is divided into $n$ layers, each of which is made of isotropic material and endowed with its thermophysical characteristics (thermal conductivity $\lambda$, specific heat $c$, and density $\rho$ ). There is an imperfect thermal contact between the layers. On the limiting surfaces, there is convective heat exchange with the environment, i. e. Newton-Richman conditions are met.

In the general case, such a statement of the problem is reduced to finding the solution of a one-parameter family of differential equations of thermal conductivity.

$$
c(r) \rho(r) \frac{\partial t_{l}(r, \tau)}{\partial \tau}=\frac{1}{r^{l}} \frac{\partial}{\partial r}\left(r^{l} \lambda(r) \frac{\partial t_{l}(r, \tau)}{\partial r}\right), \quad l=0,1,2,
$$

where $l$ is body shape ratio. So, if $l=0$, it is a multilayer flat construction; $l=1-$ a multilayer hollow cylinder; $l=2-\mathrm{a}$ multilayer hollow ball.

Since there is an imperfect thermal contact between the layers, it is necessary to record the conjugation conditions [17]

$$
\left\{\begin{array}{l}
\lambda_{i+1} \frac{\partial t_{l, i+1}}{\partial r}\left(r_{i+1}, \tau\right)-\lambda_{i} \frac{\partial t_{l, i}}{\partial r}\left(r_{i+1}, \tau\right)=0 \\
t_{l, i+1}\left(r_{i+1}, \tau\right)-t_{l, i}\left(r_{i+1}, \tau\right)=\frac{1}{\alpha_{i+1}} \lambda_{i} \frac{\partial t_{l, i}}{\partial r}\left(r_{i+1}, \tau\right)
\end{array},\right.
$$

$\alpha_{i+1}$ is the heat transfer coefficient between two inner adjacent layers. To (1) should also be added boundary conditions of the third kind

$$
\left\{\begin{array}{l}
\lambda \frac{\partial t_{l}}{\partial r}\left(r_{0}, \tau\right)=\alpha_{0}\left(t_{l}\left(r_{0}, \tau\right)-\psi_{0}(\tau)\right) \\
-\lambda \frac{\partial t_{l}}{\partial r}\left(r_{n}, \tau\right)=\alpha_{n}\left(t_{l}\left(r_{n}, \tau\right)-\psi_{n}(\tau)\right)
\end{array},\right.
$$

and the initial condition

$$
t_{l}(r, 0)=\varphi_{l}(r) .
$$

Note that $\psi_{0}(\tau)$ and $\psi_{n}(\tau)$ are ambient temperatures outside the near-surface thermal layers, while $\alpha_{0}$ and $\alpha_{n}$ are corresponding heat transfer coefficients on surfaces $r=r_{0}$ and $r=r_{n}$.

In the future we will use the following notation [12]: $\theta_{i}-$ characteristic function of the semi-open gap $\left[r_{i}, r_{i+1}\right)$, so, $\theta_{i}=\left\{\begin{array}{l}1, \text { if } r \in\left[r_{i}, r_{i+1}\right) \\ 0, \text { if } r \notin\left[r_{i}, r_{i+1}\right)\end{array} ; \quad \lambda(r)=\sum_{i=0}^{n-1} \lambda_{i} \theta_{i} ; \quad c(r) \cdot \rho(r)=\sum_{i=0}^{n-1} c_{i} \cdot \rho_{i} \cdot \theta_{i} ;\right.$ $\varphi_{l}(r)=\sum_{i=0}^{n-1} \varphi_{l, i} \cdot \theta_{i} ; \quad \lambda_{i}, \quad c_{i}, \quad \rho_{i}, \quad \alpha_{i}>0 \in R ; \quad \forall i=\overline{0, n-1}$ $r^{l} \lambda t_{l, r}^{\prime} \stackrel{d f}{=} t_{l}^{[1]}(r, \tau)$ - quasi-derivative [17], $q=\frac{t_{l}^{[1]}(r, \tau)}{r^{l}}-$ heat flux density.
Entering the notation of the quasi-derivative and multiplying conditions (2) and (3) by $r^{l}$, we will receive

$$
\begin{gathered}
\left\{\begin{array}{l}
t_{l, i+1}^{[1]}\left(r_{i+1}, \tau\right)-t_{l, i}^{[1]}\left(r_{i+1}, \tau\right)=0 \\
t_{l, i+1}\left(r_{i+1}, \tau\right)-t_{l, i}\left(r_{i+1}, \tau\right)=\frac{1}{r_{i+1}^{l} \alpha_{i+1}} t_{l, i}^{[1]}\left(r_{i+1}, \tau\right)
\end{array}\right. \\
\left\{\begin{array}{l}
\alpha_{0} r_{0}^{l} t,\left(r_{0}, \tau\right)-t_{l}^{[1]}\left(r_{0}, \tau\right)=\alpha_{0} r_{0}^{l} \psi_{0}(\tau) \\
\alpha_{n} r_{n}^{l} t_{l}\left(r_{n}, \tau\right)+t_{l}^{[1]}\left(r_{n}, \tau\right)=\alpha_{n} r_{n}^{l} \psi_{n}(\tau)
\end{array}\right.
\end{gathered}
$$

Reduction method. Following, for example, [12, 17] we will look for a solution to the problem (1-4) in the form of the sum of two interconnected functions

$$
t_{l}(r, \tau)=u_{l}(r, \tau)+v_{l}(r, \tau)
$$

Either of them, $u_{l}(r, \tau)$ or $v_{l}(r, \tau)$ can be selected in a special way, then the other will be determined unambiguously.

Function selection $u_{l}(r, \tau)$ and mixed task for $v_{l}(r, \tau)$. Let us define $u_{l}(r, \tau)$ as a solution of equation [17]

$$
\frac{1}{r^{l}}\left(r^{l} \lambda u_{l}^{\prime}\right)^{\prime}=0
$$

with conjugation conditions [17]

$$
\left\{\begin{array}{l}
u_{l, i+1}^{[1]}\left(r_{i+1}, \tau\right)-u_{l, i}^{[1]}\left(r_{i+1}, \tau\right)=0 \\
u_{l, i+1}\left(r_{i+1}, \tau\right)-u_{l, i}\left(r_{i+1}, \tau\right)=\frac{1}{r_{i+1}^{l} \alpha_{i+1}} u_{l, i}^{[1]}\left(r_{i+1}, \tau\right),
\end{array}\right.
$$

and boundary conditions

$$
\left\{\begin{array}{l}
\alpha_{0} r_{0}^{l} u_{l}\left(r_{0}, \tau\right)-u_{l}^{[1]}\left(r_{0}, \tau\right)=\alpha_{0} r_{0}^{l} \psi_{0}(\tau) \\
\alpha_{n} r_{n}^{l} u_{l}\left(r_{n}, \tau\right)+u_{l}^{[1]}\left(r_{n}, \tau\right)=\alpha_{n} r_{n}^{l} \psi_{n}(\tau)
\end{array}\right.
$$

and we will consider $\tau$ as a parameter. Here, as indicated above $u_{l}^{[1]}(r, \tau) \stackrel{d f}{=} r^{l} \lambda u_{l}^{\prime}$.

On the basis of the image (5) we will rewrite (1) in the form

$$
\begin{gathered}
c \rho \frac{\partial u_{l}(r, \tau)}{\partial \tau}+c \rho \frac{\partial v_{l}(r, \tau)}{\partial \tau}= \\
=\frac{1}{r^{l}} \frac{\partial}{\partial r}\left(r^{l} \lambda \frac{\partial u_{l}(r, \tau)}{\partial r}\right)+\frac{1}{r^{l}} \frac{\partial}{\partial r}\left(r^{l} \lambda \frac{\partial v_{l}(r, \tau)}{\partial r}\right) .
\end{gathered}
$$

Consider that $u_{l}(r, \tau)$ is the solution of problem (6-8), then in (9) $\frac{1}{r^{l}} \frac{\partial}{\partial r}\left(r^{l} \lambda \frac{\partial u_{l}(r, \tau)}{\partial r}\right) \equiv 0$ should be put and we arrive at an inhomogeneous differential equation for the function $v_{l}(r, \tau)$

$$
c \rho \frac{\partial v_{l}(r, \tau)}{\partial \tau}=\frac{1}{r^{l}} \frac{\partial}{\partial r}\left(r^{l} \lambda \frac{\partial v_{l}(r, \tau)}{\partial r}\right)-c \rho \frac{\partial u_{l}(r, \tau)}{\partial \tau},
$$

with conjugation conditions

$$
\left\{\begin{array}{l}
v_{l, i+1}^{[1]}\left(r_{i+1}, \tau\right)-v_{l, i}^{[1]}\left(r_{i+1}, \tau\right)=0 \\
v_{l, i+1}\left(r_{i+1}, \tau\right)-v_{l, i}\left(r_{i+1}, \tau\right)=\frac{1}{r_{i+1}^{l} \alpha_{i+1}} v_{l, i}^{[1]}\left(r_{i+1}, \tau\right)
\end{array} .\right.
$$

Note that the function $\frac{\partial u_{l}(r, \tau)}{\partial \tau}$ in right part is considered to be known, because $u_{l}(r, \tau)$ is a known part which we find as a solution of problem (6-8) further. Because $u_{l}(r, \tau)$ is valid for conditions (8), then the image (5) implies zero boundary conditions for $v_{l}(r, \tau)$

$$
\left\{\begin{array}{l}
\alpha_{0} r_{0}^{l} v_{l}\left(r_{0}, \tau\right)-v_{l}^{[1]}\left(r_{0}, \tau\right)=0 \\
\alpha_{n} r_{n}^{l} v_{l}\left(r_{n}, \tau\right)+v_{l}^{[1]}\left(r_{n}, \tau\right)=0
\end{array}\right.
$$


and the initial condition takes the form

$$
v_{l}(r, 0)=f_{l}(r) \equiv \varphi_{l}(r)-u_{l}(r, 0) .
$$

Solving the boundary value problem (6-8). In solving (6-8) we follow the concept of quasi-derivatives [17].

We introduce a vector $\mathbf{U}_{l}=\left(u_{l} u_{l}^{[1]}\right)^{T}$, and matrix $\mathbf{A}_{l}=$ $=\left(\begin{array}{cc}0 & \frac{1}{r^{l} \lambda} \\ 0 & 0\end{array}\right) ; \quad \mathbf{C}_{l, i+1}=\left(\begin{array}{cc}0 & \frac{1}{r_{i+1}^{l} \alpha_{i+1}} \\ 0 & 0\end{array}\right)$. Then the quasi-differential equation (6), as is easy to see, is reduced to an equivalent system of first-order differential equations [12].

$$
\mathbf{U}_{l}^{\prime}=\mathbf{A}_{l} \mathbf{U}_{l},
$$

with impulse action [17]

$$
\mathbf{U}_{l, i+1}\left(r_{i+1}\right)-\mathbf{U}_{l, i}\left(r_{i+1}\right)=\mathbf{C}_{l, i+1} \cdot \mathbf{U}_{l, i}\left(r_{i+1}\right) .
$$

Boundary conditions (8) are also written in vector form [12]

$$
\mathbf{P}_{l} \cdot \mathbf{U}_{l}\left(r_{0}\right)+\mathbf{Q}_{l} \cdot \mathbf{U}_{l}\left(r_{n}\right)=\Gamma_{l}(\tau),
$$

where $\mathbf{P}_{l}, \mathbf{Q}_{l}$ and $\Gamma_{l}(\tau)$ have a structure

$$
\begin{aligned}
& \mathbf{P}_{l}=\left(\begin{array}{cc}
r_{0}^{l} \alpha_{0} & -1 \\
0 & 0
\end{array}\right) ; \quad \mathbf{Q}_{l}=\left(\begin{array}{cc}
0 & 0 \\
r_{n}^{l} \alpha_{n} & 1
\end{array}\right) ; \\
& \Gamma_{l}(\tau)=\left(r_{0}^{l} \alpha_{0} \psi_{0}(\tau), \quad r_{n}^{l} \alpha_{n} \psi_{n}(\tau)\right)^{T} .
\end{aligned}
$$

At each interval $\left[r_{i}, r_{i+1}\right)$ system looks like

$$
\mathbf{U}_{l, i}^{\prime}=\mathbf{A}_{l, i} \mathbf{U}_{l, i} ; \quad \mathbf{A}_{l, i}=\left(\begin{array}{cc}
0 & \frac{1}{r^{l} \lambda_{i}} \\
0 & 0
\end{array}\right) .
$$

Cauchy matrix $\mathbf{B}_{i, l}(r, s)$ of system looks like [12]

$$
\mathbf{B}_{i, l}(r, s)=\left(\begin{array}{cc}
1 & K_{i, l}(r, s) \\
0 & 1
\end{array}\right), \quad l=0,1,2,
$$

where $K_{i, l}(r, s)=\frac{1}{\lambda_{i}} \int_{s}^{r} \frac{d z}{z^{l}}$.

Solution $\mathbf{U}_{l, i}(r)$ of the corresponding homogeneous system (17) on the interval $\left[r_{i}, r_{i+1}\right)$ will be searched for in the form

$$
\mathbf{U}_{l, i}(r)=\mathbf{B}_{l, i}\left(r, r_{i}\right) \mathbf{P}_{l, i},
$$

where $\mathbf{P}_{l, i}$ is still unknown vector.

Similarly on the interval $\left[r_{i+1}, r_{i+2}\right)$

$$
\mathbf{U}_{l, i+1}(r)=\mathbf{B}_{l, i+1}\left(r, r_{i+1}\right) \mathbf{P}_{l, i+1} .
$$

At the point $r=r_{i}$ the conjugation condition (15) must be satisfied. Applying it to equations (18 and 19), we obtain

$$
\mathbf{P}_{l, i+1}=\left(\mathbf{E}+\mathbf{C}_{l, i+1}\right) \mathbf{B}_{l, i}\left(r_{i+1}, r_{i}\right) \cdot \mathbf{P}_{l, i} .
$$

Let us denote

$$
\begin{gathered}
\left(\mathbf{E}+\mathbf{C}_{l, i+1}\right)=\widetilde{\mathbf{C}}_{l, i+1} ; \\
\mathbf{B}_{l}\left(r_{p}, r_{q}\right) \stackrel{d f}{=} \widetilde{\mathbf{C}}_{l, p} \mathbf{B}_{l, p-1}\left(r_{p}, r_{p-1}\right) \times \widetilde{\mathbf{C}}_{l, p-1} \mathbf{B}_{l, p-2}\left(r_{p-1}, r_{p-2}\right) \times \ldots \times \\
\times \widetilde{\mathbf{C}}_{l, q+1} \mathbf{B}_{l, q}\left(r_{q+1}, r_{q}\right) .
\end{gathered}
$$

Based on relation (18) for arbitrary $k>0$ by the method of mathematical induction on the index $k$ we obtain

$$
\mathbf{P}_{l, m+k}=\mathbf{B}_{l}\left(r_{m+k}, r_{m}\right) \cdot \mathbf{P}_{l, m} .
$$

Encharging $m=0$, we obtain

$$
\mathbf{P}_{l, k}=\mathbf{B}_{l}\left(r_{k}, r_{0}\right) \cdot \mathbf{P}_{l, 0} .
$$

Using boundary conditions (8), we obtain an expression for the calculation $\mathbf{P}_{l, 0} \equiv \mathbf{U}_{l, 0}\left(r_{0}\right)$

$$
\begin{aligned}
& \mathbf{P}_{l} \cdot \mathbf{U}_{l, 0}\left(r_{0}\right)+\mathbf{Q}_{l} \cdot \mathbf{U}_{l, n}\left(r_{n}\right)=\Gamma_{l} \Rightarrow \\
\Rightarrow & \mathbf{P}_{l} \cdot \mathbf{P}_{l, 0}+\mathbf{Q}_{l}\left(\mathbf{B}_{l}\left(r_{n}, r_{0}\right) \cdot \mathbf{P}_{l, 0}\right)=\Gamma_{l} \Rightarrow \\
\Rightarrow & \mathbf{P}_{l, 0}=\left(\mathbf{P}_{l}+\mathbf{Q}_{l} \cdot \mathbf{B}_{l}\left(r_{n}, r_{0}\right)\right)^{-1} \cdot \Gamma_{l} .
\end{aligned}
$$

At each interval $\left[r_{i}, r_{i+1}\right)$ the solution of problem (14-16) has the form of a vector function $\mathbf{U}_{l, i}(r)[12,17]$

$$
\mathbf{U}_{l, i}(r)=\mathbf{B}_{l, i}\left(r, r_{i}\right) \cdot \mathbf{B}_{l}\left(r_{i}, r_{0}\right) \cdot \mathbf{P}_{l, 0} \cdot \theta_{i} \cdot
$$

The first coordinate of the vector function $\mathbf{U}_{l, i}(r)$ is the function we are searching for $u_{l, i}(r, \tau)$, and the second $\left(u_{l, i}^{[1]}(r)\right)$ is its quasi-derivative.

Solution (21) exists and is unique if $\operatorname{det}\left(\mathbf{P}_{l}+\mathbf{Q}_{l} \mathbf{B}_{l}\left(r_{n}, r_{0}\right)\right) \neq 0$.

Expression (21) makes it possible to write the solution on the whole interval $\left[r_{0}, r_{n}\right]$ using characteristic functions $\theta_{i}$ as

$$
u_{l}(r, \tau)=\sum_{i=0}^{n-1} u_{l, i}(r, \tau) \theta_{i}
$$

Fourier method and eigenvalue problem. We will look for nontrivial partial solutions of a homogeneous differential equation

$$
c \rho \frac{\partial v_{l}(r, \tau)}{\partial \tau}=\frac{1}{r^{l}} \frac{\partial}{\partial r}\left(r^{l} \lambda \frac{\partial v_{l}(r, \tau)}{\partial r}\right),
$$

with conditions (11) and (12) as [17]

$$
v_{l}(r, \tau)=e^{-\omega_{l} \tau} \cdot R_{l}(r),
$$

where $\omega_{l}$ is the parameter; $R_{l}(r)$ is the unknown function.

Substituting the right part (23) in (22) we come to

$$
\left(r^{l} \lambda R_{l}^{\prime}\right)^{\prime}+\omega_{l} c \rho r^{l} R_{l}=0
$$

with conjugation conditions

$$
\left\{\begin{array}{l}
R_{l, i+1}^{[1]}\left(r_{i+1}\right)-R_{l, i}^{[1]}\left(r_{i+1}\right)=0 \\
R_{l, i+1}\left(r_{i+1}\right)-R_{l, i}\left(r_{i+1}\right)=\frac{1}{r_{i+1}^{l} \alpha_{i+1}} R_{l, i}^{[1]}\left(r_{i+1}\right)
\end{array}\right.
$$

and boundary conditions

$$
\left\{\begin{array}{c}
r_{0}^{l} \alpha_{0} R_{l}\left(r_{0}\right)-R_{l}^{[1]}\left(r_{0}\right)=0 \\
r_{n}^{l} \alpha_{n} R_{l}\left(r_{n}\right)+R_{l}^{[1]}\left(r_{n}\right)=0
\end{array} .\right.
$$

The second condition (25) shows that the solution of equation (24) at points $r=r_{i}, i=\overline{1, n-1}$ have gaps of the first kind. In this connection, (24-26) is a certain generalization of the classical problem to eigenvalues.

Constructive construction of own functions. We introduce the following notation: $R_{l}^{[1]}=r^{l} \lambda R_{l}^{\prime}-$ quasi-derivative, vector $R_{l}=\left(R_{l}, R_{l}^{[1]}\right)^{T}$ and matrix $\widetilde{\mathbf{A}}_{l}=\left(\begin{array}{cc}0 & \frac{1}{r^{l} \lambda} \\ -\omega_{l} r^{l} c \rho & 0\end{array}\right)$. Then quasi-differential equation (24) reduces to its equivalent system of first-order differential equations

$$
\mathbf{R}_{l}{ }^{\prime}=\widetilde{\mathbf{A}}_{l} \mathbf{R}_{l},
$$

with conjugation conditions

$$
\mathbf{R}_{l, i+1}\left(r_{i+1}\right)-\mathbf{R}_{l, i}\left(r_{i+1}\right)=\mathbf{C}_{l, i+1} \mathbf{R}_{l, i}\left(r_{i+1}\right),
$$

and boundary conditions

$$
\mathbf{P}_{l} \mathbf{R}_{l}\left(r_{0}\right)+\mathbf{Q}_{l} \mathbf{R}_{l}\left(r_{n}\right)=0 .
$$

At each of the intervals of the interval $\left[r_{i}, r_{i+1}\right)$ system looks like

$$
\mathbf{R}_{l, i}^{\prime}=\widetilde{\mathbf{A}}_{l, i} \mathbf{R}_{l, i}, \quad i=\overline{0, n-1} .
$$

Cauchy matrix $\widetilde{\mathbf{B}}_{l, i}\left(r, s, \omega_{l}\right)$ of system looks like 


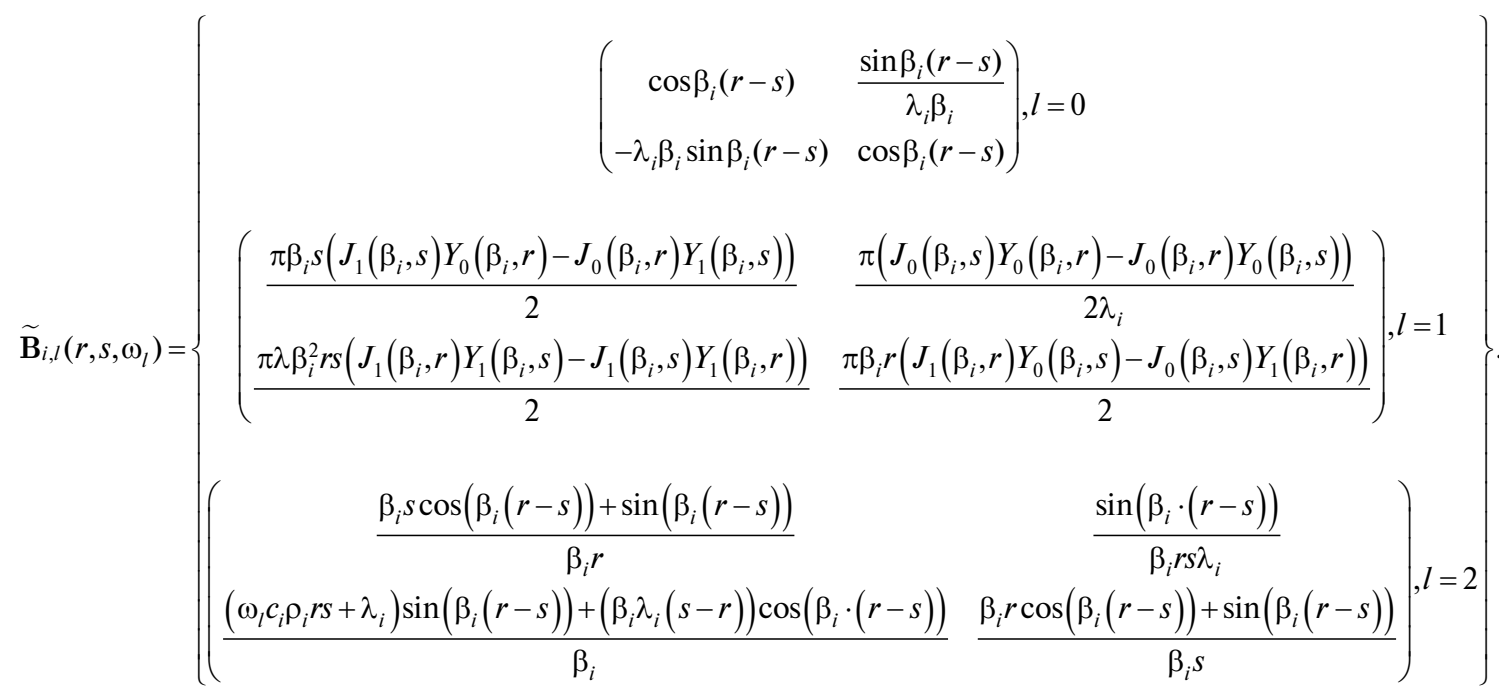

Where we note that $\beta_{i}=\sqrt{\frac{\omega_{l} c_{i} \rho_{i}}{\lambda_{i}}}, J_{0}$ and $N_{0}$ are Bessel and

Neumann functions of zero order, respectively.

Similarly, as in formula (20) we write

$$
\begin{aligned}
\widetilde{\mathbf{B}}_{l}\left(r_{k}, r_{i}, \omega_{l}\right)=\stackrel{d f}{=} \widetilde{\mathbf{C}}_{l, k} & \widetilde{\mathbf{B}}_{l, k-1}\left(r_{k}, r_{k-1}, \omega_{l}\right) \cdot \widetilde{\mathbf{C}}_{l, k-1} \widetilde{\mathbf{B}}_{l, k-2}\left(r_{k-1}, r_{k-2}, \omega_{l}\right) \cdot \ldots \times \\
& \times \widetilde{\mathbf{C}}_{l, i+1} \widetilde{\mathbf{B}}_{l, i}\left(r_{i+1}, r_{i}, \omega_{l}\right), \quad k>i .
\end{aligned}
$$

Also note that

$$
\begin{aligned}
& \widetilde{\mathbf{B}}_{l}\left(r, r_{0}, \omega_{l}\right) \stackrel{d f}{=} \sum_{i=0}^{n-1} \widetilde{\mathbf{B}}_{i, l}\left(r, r_{i}, \omega_{l}\right) \cdot \widetilde{\mathbf{B}}_{l}\left(r_{i}, r_{0}, \omega_{l}\right) \cdot \theta_{i} ; \\
& \widetilde{\mathbf{B}}_{l}\left(r_{n}, r_{0}, \omega_{l}\right)=\left(\begin{array}{ll}
b_{11}\left(\omega_{l}\right) & b_{12}\left(\omega_{l}\right) \\
b_{21}\left(\omega_{l}\right) & b_{22}\left(\omega_{l}\right)
\end{array}\right) .
\end{aligned}
$$

A non-trivial solution $\mathbf{R}_{l}\left(r, \omega_{l}\right)$ of system (29) is sought in the form

$$
\mathbf{R}_{l}\left(r, \omega_{l}\right)=\widetilde{\mathbf{B}}_{l}\left(r, r_{0}, \omega_{l}\right) \cdot \mathbf{C}_{l}
$$

where $\mathbf{C}_{l}=\left(C_{l, 1}, C_{l, 2}\right)^{T}$ - some nonzero vector.

Applying to both parts of equation (30) of the boundary conditions in the form (28), we obtain

$$
\begin{gathered}
\mathbf{P}_{l} \cdot \mathbf{R}_{l}\left(r_{0}, \omega_{l}\right)+\mathbf{Q}_{l} \cdot \mathbf{R}_{l}\left(r_{n}, \omega_{l}\right)= \\
=\left[\mathbf{P}_{l} \cdot \widetilde{\mathbf{B}}_{l}\left(r_{0}, r_{0}, \omega_{l}\right)+\mathbf{Q}_{l} \cdot \widetilde{\mathbf{B}}_{l}\left(r_{n}, r_{0}, \omega_{l}\right)\right] \cdot \mathbf{C}_{l}=\mathbf{0},
\end{gathered}
$$

or noting that $\widetilde{\mathbf{B}}_{l}\left(r_{0}, r_{0}, \omega_{l}\right)=E$, where $E$ is a unit matrix, we come to equality

$$
\left[\mathbf{P}_{l}+\mathbf{Q}_{l} \cdot \widetilde{\mathbf{B}}_{l}\left(r_{n}, r_{0}, \omega_{l}\right)\right] \cdot \mathbf{C}_{l}=\mathbf{0}
$$

For the existence of a nonzero vector $\mathbf{C}_{l}$ in (31) it is necessary and sufficient to fulfill the condition

$$
\operatorname{det}\left[\mathbf{P}_{l}+\mathbf{Q}_{l} \cdot \widetilde{\mathbf{B}}_{l}\left(r_{n}, r_{0}, \omega_{l}\right)\right]=0 .
$$

Proposition 1. The characteristic equation of the problem for eigenvalues (24-26) has the form (32).

As it is known $[12,18]$, the roots of the characteristic equation (32), which are the eigenvalues of problem (24-26), are positive and different.

To find a nonzero vector $\mathbf{C}_{l}=\left(C_{l, 1}, C_{l, 2}\right)^{T}$ substitute $\omega_{l, k}$ instead $\omega$ in equality (32). Then we come to vector equality

$$
\begin{gathered}
{\left[\left(\begin{array}{cc}
r_{0}^{l} \alpha_{0} & -1 \\
0 & 0
\end{array}\right)\left(\begin{array}{cc}
0 & 0 \\
r_{n}^{l} \alpha_{n} & 1
\end{array}\right) \cdot\left(\begin{array}{ll}
b_{11}\left(\omega_{l, k}\right) & b_{12}\left(\omega_{l, k}\right) \\
b_{21}\left(\omega_{l, k}\right) & b_{22}\left(\omega_{l, k}\right)
\end{array}\right)\right] \cdot\left(\begin{array}{l}
C_{l, 1} \\
C_{l, 2}
\end{array}\right)=\left(\begin{array}{l}
0 \\
0
\end{array}\right) \Rightarrow} \\
\Rightarrow\left(\begin{array}{c}
\alpha_{0} \\
\left(r_{n}^{l} \alpha_{n} b_{11}\left(\omega_{l, k}\right)+b_{21}\left(\omega_{l, k}\right)\right)
\end{array}\right. \\
\times\left(\begin{array}{l}
\left.C_{l, 1}^{l} \alpha_{n} b_{12}\left(\omega_{l, k}\right)+b_{22}\left(\omega_{l, k}\right)\right) \\
C_{l, 2}
\end{array}\right)=\left(\begin{array}{l}
0 \\
0
\end{array}\right),
\end{gathered}
$$

which is equivalent to a system of equations

$$
\left\{\begin{array}{l}
r_{0}^{l} \alpha_{0} C_{l, 1}-C_{l, 2}=0 \\
\left(r_{n}^{l} \alpha_{n} b_{11}\left(\omega_{l, k}\right)+b_{21}\left(\omega_{l, k}\right)\right) \cdot C_{l, 1}+\left(r_{n}^{l} \alpha_{n} b_{12}\left(\omega_{l, k}\right)+.\right. \\
\left.+b_{22}\left(\omega_{l, k}\right)\right) \cdot C_{l, 2}=0
\end{array}\right.
$$

Since the determinant of this system is zero, the system (33) has nonzero solutions $C_{l, 1} \neq 0, C_{l, 2} \neq 0 \in \mathbb{R}$. Putting, for example $C_{l, 2}=1$, we have $C_{l, 1}=\frac{1}{r_{0}^{l} \alpha_{0}}$, that is

$$
\mathbf{C}=\left(\frac{1}{r_{0}^{l} \alpha_{0}}, 1\right)^{T}
$$

Setting the form of a non-trivial eigenvector $\mathbf{C}$, which corresponds to its own values $\omega_{l, k}$, we receive:

Proposition 2. The eigenvectors of the system of differential equations with impulse action (27) have the following structure

$$
\mathbf{R}_{l, k, i}\left(r, \omega_{l, k}\right)=\widetilde{\mathbf{B}}_{l, i}\left(r, r_{i}, \omega_{l, k}\right) \cdot \widetilde{\mathbf{B}}_{l}\left(r_{i}, r_{0}, \omega_{l, k}\right) \cdot\left(\begin{array}{c}
\frac{1}{r_{0}^{l} \alpha_{0}} \\
1
\end{array}\right), \quad i=\overline{0, n-1}
$$

Consequence. Eigen functions $R_{l, k}\left(r, \omega_{l, k}\right)$, as the first coordinates of eigenvectors $\mathbf{R}_{l, k}\left(r, \omega_{l, k}\right)$, can be written as

$$
R_{l, k, i}\left(r, \omega_{l, k}\right)=(1,0) \cdot \widetilde{\mathbf{B}}_{l, i}\left(r, r_{i}, \omega_{l, k}\right) \cdot \widetilde{\mathbf{B}}_{l}\left(r_{i}, r_{0}, \omega_{l, k}\right) \cdot\left(\begin{array}{c}
\frac{1}{r_{0}^{l} \alpha_{0}} \\
1
\end{array}\right) .
$$

Development of some piecewise continuous function $g(r)$, having gaps of the first kind at points $r_{i}, i=\overline{1, n-1}$ in the Fourier series by eigen functions $R_{l, k}\left(r, \omega_{l, k}\right)$ has the form [17]

$$
g_{l}(r) \equiv \sum_{i=0}^{n-1} g_{l, i} \theta_{i}=\sum_{k=1}^{\infty} \gamma_{l, k} \cdot R_{l, k}\left(r, \omega_{l, k}\right),
$$

where Fourier coefficients $\gamma_{l, k}$ are calculated by the formula 


$$
\begin{gathered}
\gamma_{l, k}=\frac{1}{\left\|R_{l, k}\right\|^{2}} \int_{r_{0}}^{r_{n}} c \rho g_{l}(r) R_{l, k}\left(r, \omega_{l, k}\right) r^{l} d r= \\
=\frac{1}{\left\|R_{l, k}\right\|^{2}} \sum_{i=0}^{n-1} c_{i} \rho_{i} \int_{r_{i}}^{r_{i+1}} g_{l, i}(r) R_{l, k, i}\left(r, \omega_{l, k}\right) r^{l} d r .
\end{gathered}
$$

Here $\left\|R_{l, k}\right\|^{2}$ is the square of the norm of eigenfunctions $R_{l, k}\left(r, \omega_{l, k}\right)$

$$
\left\|R_{l, k}\right\|^{2}=\int_{r_{0}}^{r_{n}} c \rho r^{l} R_{l, k}^{2}\left(r, \omega_{l, k}\right) d r=\sum_{i=0}^{n-1} c_{i} \rho_{i} \int_{r_{i}}^{r_{i+1}} R_{l, k . i}^{2}\left(r, \omega_{l, k}\right) r^{l} d r .
$$

To construct the solution of the problem (10-13), we apply the method of eigenfunctions [17, 18], which consists in the fact that we will look for the solution of this problem in the form

$$
v_{l}(r, \tau)=\sum_{k=1}^{\infty} T_{l, k}(\tau) \cdot R_{l, k}\left(r, \omega_{l, k}\right),
$$

where $T_{l, k}(\tau)$ is unknown function.

Because $\frac{\partial u_{l}}{\partial \tau}$ is included in the right-hand side of equation (10), we develop it into the Fourier series by eigenfunctions (34) of the boundary value problem (24-26)

$$
\frac{\partial u_{l}}{\partial \tau}=\sum_{k=1}^{\infty} u_{l, k}(\tau) \cdot R_{l, k}\left(r, \omega_{l, k}\right),
$$

and variable $\tau$ is considered as a parameter.

Substituting (35) into (22), and taking into account the development of (36), we obtain equality

$$
\begin{gathered}
c \rho \sum_{k=1}^{\infty} T_{l, k}^{\prime}(\tau) \cdot R_{l, k}\left(r, \omega_{l, k}\right)= \\
=\frac{1}{r^{l}} \sum_{k=1}^{\infty} T_{l, k}(\tau) \cdot\left(r^{l} \lambda R_{l, k}^{\prime}\left(r, \omega_{l, k}\right)\right)^{\prime}-c \rho \sum_{k=1}^{\infty} u_{l, k}(\tau) \cdot R_{l, k}\left(r, \omega_{l, k}\right),
\end{gathered}
$$

which after taking into account the equality $\left(r_{l} \lambda R_{l, k}^{\prime}\right)+\omega^{k} r_{l} c \rho R_{l, k} \equiv$ $\equiv 0$, and cuts on $c \rho \neq 0$ will take the form

$$
\sum_{k=1}^{\infty}\left[T_{l, k}^{\prime}(\tau)+\omega_{l, k} T_{l, k}(\tau)+u_{l, k}(\tau)\right] \cdot R_{l, k}\left(r, \omega_{l, k}\right)=0 .
$$

Equating the Fourier coefficients of the series (37) to zero we obtain an infinite set of differential equations

$$
T_{l, k}^{\prime}(\tau)+\omega_{l, k} T_{l, k}(\tau)+u_{l, k}(\tau)=0, \quad k=1,2,3, \ldots
$$
form

The general solution of each of these equations has the

$$
T_{l, k}(t)=C_{l, k} \cdot e^{-\omega_{l, k} \tau}-\int_{0}^{\tau} e^{-\omega_{l, k}(\tau-s)} \cdot u_{l, k}(s) d s, \quad k=1,2,3, \ldots .
$$

where $C_{l, k}$ is unknown constants.

To find them, we will develop a function $f(r)$ (from the initial condition (13)) in the Fourier series by the system of eigenfunctions (34) of the boundary value problem (24-26)

$$
v_{l}(r, 0)=f_{l}(r)=\sum_{k=1}^{\infty} f_{l, k} R_{l, k}\left(r, \omega_{l, k}\right),
$$

where $f_{l, k}$ is corresponding Fourier coefficients.

Based on (38) we establish that

$$
T_{l, k}(0)=C_{l, k},
$$

and given the expression (35) we obtain

$$
v_{l}(r, 0)=\sum_{k=1}^{\infty} T_{l, k}(0) \cdot R_{l, k}\left(r, \omega_{l, k}\right) .
$$

Equating expressions (39-41), we obtain that $C_{l, k}=f_{l, k}$.
Finally, the solution of the mixed problem $(10-13)$ is written in the form of a series [12]

$$
\begin{gathered}
v_{l}(r, \tau)=\sum_{k=1}^{\infty}\left[f_{l, k} \cdot e^{-\omega_{l, k} \tau}-\int_{0}^{\tau} e^{-\omega_{l, k}(\tau-s)} u_{l, k}(s) d s\right] \cdot R_{l, k}\left(r, \omega_{l, k}\right)= \\
=\sum_{i=0}^{n-1} v_{l, i}(r, \tau) \cdot \theta_{l, i},
\end{gathered}
$$

where

$$
v_{l, i}(r, \tau)=\sum_{k=1}^{\infty}\left[f_{l, k} \cdot e^{-\omega_{l, k} \tau}-\int_{0}^{\tau} e^{-\omega_{l, k}(\tau-s)} u_{l, k}(s) d s\right] \cdot R_{l, k, i}\left(r, \omega_{l, k}\right) .
$$

Based on the image (4), the solution of the problem (1-4) is obtained.

$$
t_{l}(r, \tau)=\sum_{i=0}^{n-1}\left[u_{l, i}(r, \tau)+v_{l, i}(r, \tau)\right] \cdot \theta_{i},
$$

where $u_{l, i}(r, \tau)$ and $v_{l, i}(r, \tau)$ are defined by formulas (21) and (42), respectively.

It should be noted that in [19] the verification of the presented method was carried out in comparison with the results of field fire tests.

Numerical implementation of the method (model example).

Consider the problem of heating an eight-layer structure (flat, cylindrical and spherical ones) which is made of different isotropic layers. At the initial time, the temperature of the structure and the environment is $20^{\circ} \mathrm{C}$. The ambient temperature that washes the outer surface varies according to the law of thestandard temperature of the fire $\psi_{n}(\tau)=345 \lg \left(1+\frac{8 \tau}{60}\right)+20$, at the heat transfer coefficient between the medium and the surface $\alpha_{n}=25 \mathrm{~W} / \mathrm{m}^{2} \cdot{ }^{\circ} \mathrm{C}$. [20]. The temperature of the medium that washes the inner surface is constant and is $\psi_{0}(\tau)=$ $=20{ }^{\circ} \mathrm{C}-$ heat transfer coefficient $\alpha_{0}=4 \mathrm{~W} / \mathrm{m}^{2} \cdot{ }^{\circ} \mathrm{C}$. Thermal characteristics of the structure for calculation are as follows: layer thickness $[\mathrm{m}]-r_{0}=0.01 ; r_{1}=0.03 ; r_{2}=0.013 ; r_{3}=0.018$; $r_{4}=0.25 ; r_{5}=0.34 ; r_{6}=0.45 ; r_{7}=0.48 ; r_{8}=0.5$; thermal conductivity coefficients $\left[\mathrm{W} / \mathrm{m}^{2} \cdot{ }^{\circ} \mathrm{C}\right]-\lambda_{0}=209 ; \lambda_{1}=1.55 ; \lambda_{2}=64$; $\lambda_{3}=393 ; \lambda_{4}=52 ; \lambda_{5}=2.91 ; \lambda_{6}=34.6 ; \lambda_{7}=58$; specific heat $\left[\mathrm{J} / \mathrm{kg} \cdot{ }^{\circ} \mathrm{C}\right]-c_{0}=894 ; c_{1}=770 ; c_{2}=389 ; c_{3}=389 ; c_{4}=420 ; c_{5}=$ $=921 ; c_{6}=130 ; c_{7}=470 ;$ density $\left[\mathrm{kg} / \mathrm{m}^{3}\right]-\rho_{0}=2680 ; \rho_{1}=$ $=2200 ; \rho_{2}=8000 ; \rho_{3}=8950 ; \rho_{4}=7270 ; \rho_{5}=2800 ; \rho_{6}=11400 ;$ $\rho_{7}=7800$; heat transfer coefficients between layers $\left[\mathrm{W} / \mathrm{m}^{2} \cdot{ }^{\circ} \mathrm{C}\right]-$ $\alpha_{1}=110 ; \alpha_{3}=180 ; \alpha_{5}=270 ; \alpha_{7}=240$.

The results of calculations of the problem are shown in Figs. 1-3.

The Figures clearly show the process of heating structures, as well as temperature gaps at the boundary of individual layers, between which there is an imperfect thermal contact. Instead, heat flux densities are continuous functions. This illustration fully corresponds to the conditions of imperfect thermal contact. The presented problem is a model that illustrates the possibilities of the proposed method.

Conclusions. In the given work the general scheme of research on processes of heat transfer in multilayer designs of various geometrical forms at the same time taking into account imperfect thermal contact between layers is offered.

For specificity, the boundary conditions of the third kind, which are the most general local conditions, are considered. In the transition to other boundary conditions, the implementation scheme does not cause any difficulties.

The work does not take into account the presence of internal heat sources. This avoids complications that are only technical in nature. Such complications could divert the reader's attention from the main idea of implementing the proposed approach. 


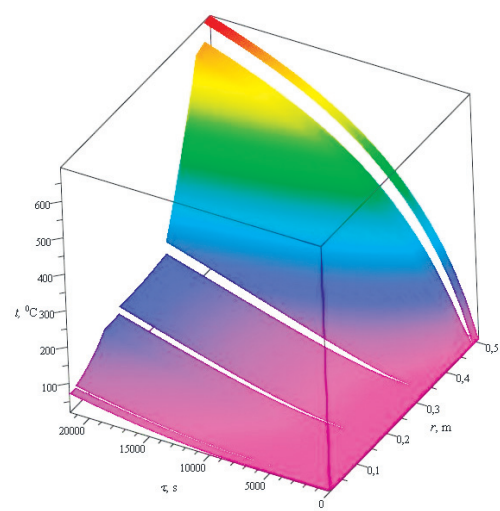

$a$

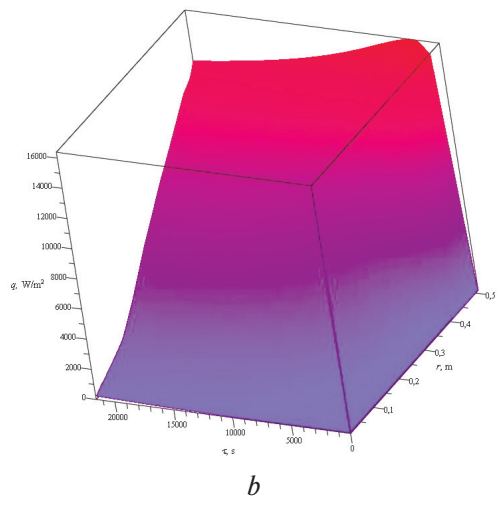

Fig. 1. Heating of a flat structure:

$a$ - temperature; $b$ - heat flux density
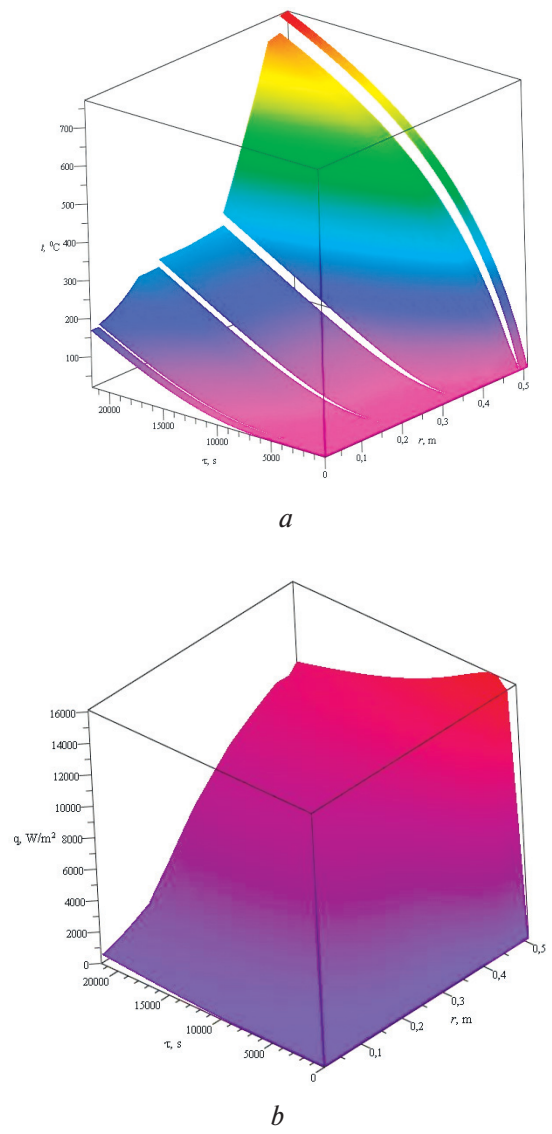

Fig. 2. Heating of a cylindrical structure:

$a$ - temperature; $b$ - heat flux density

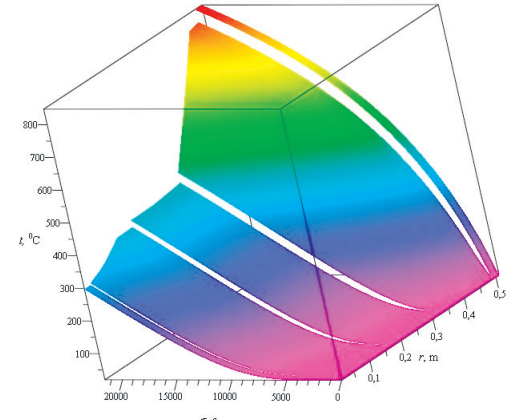

$a$

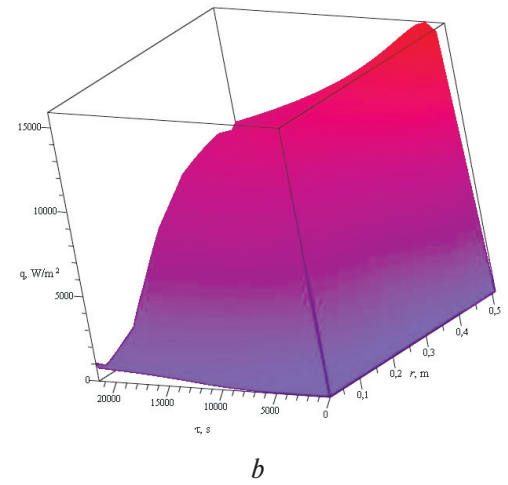

Fig. 3. Heating of a spherical structure:

$a$ - temperature; $b$ - heat flux density

The solved model examples use only the formula of the standard temperature regime of the fire, to illustrate the possibilities of the proposed method. The use of other laws of temperature change on the surfaces limiting the body does not cause any fundamental complications.

\section{References.}

1. Shatskyi, I., Ropyak, L., \& Velychkovych, A. (2020). Model of contact interaction in threaded joint equipped with spring-loaded collet. Engineering Solid Mechanics, 8(4), 301312. https://doi.org/10.5267/j.esm.2020.4.002.

2. Bulbuk, O., Velychkovych, A., Mazurenko, V., Ropyak, L., \& Pryhorovska, T. (2019). Analytical estimation of tooth strength, restored by direct or indirect restorations. Engineering Solid Mechanics, 7(3), 193-204. https://doi.org/10.5267/i. esm.2019.5.004.

3. Topchevska, K. (2017). Influence of friction power on temperature stresses during single braking. Physicochemical Mechanics of Materials, 53(5), 66-72.

4. Yang, X. J. (2017). A new integral transform operator for solving the heat-diffusion problem. Applied Mathematics Letters, 64, 193-197. https://doi.org/10.1016/j.aml.2016.09.011.

5. Yang, X. J., \& Gao, F. (2017). A new technology for solving diffusion and heat equations. Thermal Science, 21(1, Part A), 133-140. https://doi.org/10.2298/TSCI160411246Y.

6. Jiang, J., \& Zhou, J. (2020). Analytical solutions of Laplace's equation for layered media in a cylindrical domain and its application in seepage analyses. International Journal of Mechanical Sciences, 105781. https://doi.org/10.1016/j.ijmecsci.2020.105781.

7. Vidal, P., Gallimard, L., Ranc, I., \& Polit, O. (2017). Thermal and thermo-mechanical solution of laminated composite beam based on a variables separation for arbitrary volume heat source locations. Applied Mathematical Modelling, 46, 98-115. https://doi.org/10.1016/j.apm.2017.01.064.

8. Gołębiowski, J., \& Zaręba, M. (2020). Transient Thermal Field Analysis in ACCC Power Lines by the Green's Function Method. Energies, 13(1), 280. https://doi.org/10.3390/ en13010280. 
9. Norouzi, M., Rahmani, H., Birjandi, A. K., \& Joneidi, A. A. (2016). A general exact analytical solution for anisotropic non-axisymmetric heat conduction in composite cylindrical shells. International Journal of Heat and Mass Transfer, 93, 41-56. https://doi.org/10.1016/j.ijheatmasstransfer.2015.09.072.

10. Eliseev, V. N., \& Borovkova, T. V. (2014). The generalized analytical approach to calculating a stationary temperature field in objects of simple geometrical shapes. Herald of the Bauman Moscow State Technical University. Series Mechanical Engineering, (1), 46-57.

11. Eliseev, V. N., Tovstonog, V.A., \& Borovkova, T. V. (2017). Soluton algorthim of generalized non-stationary heat conduction problem in the bodies of simple geometric shapes. Herald of the Bauman Moscow State Technical University. Series Mechanical Engineering, (1), 112-128. https://doi.org/10.18698/02363941-2017-1-112-128.

12. Tatsiy, R. M., Pazen, O.Y., Vovk, S.Y., Ropyak, L.Y., \& Pryhorovska, T. O. (2019). Numerical study on heat transfer in multilayered structures of main geometric forms made of different materials. Journal of the Serbian Society for Computational Mechanics, 13(2), 36-55. https://doi.org/10.24874/jsscm.2019.13.02.04.

13. Okrepkyi, B., Pyndus, T., \& Shelestovs'kyi, B. (2019). Hot stamp pressure on elastic half-space taking into account imperfect thermal contact through thin intermediate layer. Scientific Journal of TNTU, 96(4), 14-22. https://doi.org/10.33108/visnyk tntu2019.04.013.

14. Gera, B. V. (2013). Mathematical modelling of nonideal conditions for thermal contact of layers through thing inclusion with heat source. Physical and mathematical modeling and information technology, (18), 61-72.

15. Okrepky, B. S., \& Nemish, V. M. (2014). Axes-symmetric temperature problem for a system of two layers in non-ideal termal contact. Interuniversity collection Scientific notes, (47), 131-136.

16. Yang, B., \& Liu, S. (2017). Closed-form analytical solutions of transient heat conduction in hollow composite cylinders with any number of layers. International Journal of Heat and Mass Transfer, 108, 907-917. https://doi.org/10.1016/j. ijheatmasstransfer.2016.12.020.

17. Tatsiy, R. M., Pazen, O. Yu., \& Stasiuk, M. F. (2019). Calculation of non-stationary temperature field in a multilayered plate under conditions of unique heat contact between layers. Bulletin of the Kokshetau Technical Institute of the KTIKCHSMVD of the Republic of Kazakhstan, 2(34), 40-49.

18. Tatsii, R. M., \& Pazen, O.Y. (2018). Direct (classical) method of calculation of the temperature field in a hollow multilayer cylinder. Journal of Engineering Physics and Thermophysics, 91(6), 1373-1384. https://doi.org/10.1007/s10891018-1871-3.

19. Pazen, O. (2018). Verification Results of the Presentation of the Protection of the Unsteading Temperature Field at the Concrete Construction for the Mind of Thestandard Temperature Refrigeration Fire. Bulletin of Lviv State University of Life Safety, (18), 96-101. https://doi.org/10.32447/20784643.18.20 18.10 .

20. EN 1991-1-2 (2002). Eurocode 1: Actions on structures Part 1-2: General actions - Actions on structures exposed to fire [Authority: The European Union Per Regulation 305/2011, Directive 98/34/EC, Directive 2004/18/EC]. https://doi. org/10.1002/9783433601570.ch1.

\section{Прямий метод дослідження теплообміну в багатошарових тілах основних геометричних форм при неідеальному тепловому контакті}

Львівський державний університет безпеки життєдіяльності, м. Львів, Україна, е-mail: opazen@gmail.com

Мета. Характеристика процесів теплообміну в багатошарових тілах основних геометричних форм одночасно за умов конвективного теплообміну на його поверхнях та $з$ урахуванням неідеального теплового контакту між шарами.

Методика. Був застосований прямий метод до розв'язування однопараметричної сім'ї крайових задач теорії теплопровідності. В основі цього методу є: метод редукції, концепція квазіпохідних, система диференціальних рівнянь з імпульсною дією, метод відокремлення змінних і модифікований метод власних функцій Фур'є. Варто зауважити, що застосування концепції квазіпохідних дозволяє обійти відому проблему множення узагальнених функцій, яка виникає при використанні процедури диференціювання коефіцієнтів диференціального рівняння. Така процедура, на наш погляд, ставить під сумнів еквівалентність переходу до отриманого таким шляхом диференціального рівняння з узагальненими коефіцієнтами.

Результати. Розв'язок поставленої задачі отримано в замкненому вигляді. Запропонований алгоритм не містить у собі розв'язування громіздких задач спряження. До нього входять лише: а) знаходження коренів відповідних характеристичних рівнянь; б) множення скінченної кількості відомих $(2 \times 2)$ матриць; в) обчислення визначених інтегралів; г) сумування необхідної кількості членів ряду для отримання заданої точності. В якості ілюстрації розглянуті модельні приклади нагрівання восьмишарових конструкцій за умов пожежі.

Наукова новизна. Уперше прямий метод застосований до розв'язування задачі про розподіл нестаціонарного температурного поля за товщиною багатошарових конструкцій основних геометричних форм одночасно при неідеальному тепловому контакті між шарами.

Практична значимість. Упровадження результатів дослідження дає змогу ефективно досліджувати процеси теплообміну в багатошарових конструкціях, що зустрічаються в ряді прикладних задач.

Ключові слова: теплообмін, коефіцієнт форми тіла, неідеальний тепловий контакт

\section{Прямой метод исследования теплообмена в многослойных телах основных геометрических форм при неидеальном тепловом контакте}

\section{Р. М. Таций, О. Ю. Пазен, С. Я. Вовк, Д. В.Харышын}

Львовский государственный университет безопасности жизнедеятельности, г. Львов, Украина, e-mail: opazen@ gmail.com

Цель. Характеристика процессов теплообмена в многослойных телах основных геометрических форм одновременно в условиях конвективного теплообмена на его поверхностях и с учетом неидеального теплового контакта между слоями.

Методика. Был применен прямой метод для решения однопараметрической семьи краевых задач теории теплопроводности. В основе этого метода положен: метод редукции, концепция квазипроизводных, система дифференциальных уравнений с импульсным воздействием, метод разделения переменных и модифицированный метод собственных функций Фурье. Стоит заметить, что применение концепции квазипроизводных позволяет обойти известную проблему умножения обобщенных функций, которая возникает при использовании проце- 
дуры дифференцирования коэффициентов дифференциального уравнения. Такая процедура, на наш взгляд, ставит под сомнение эквивалентность перехода к полученному таким путем дифференциальному уравнению с обобщенными коэффициентами.

Результаты. Решение поставленной задачи получено в замкнутом виде. Предложенный алгоритм не содержит в себе решения объёмных задач сопряжения. В него входят только: а) нахождение корней соответствующих характеристических уравнений; б) умножение конечного числа известных $(2 \times 2)$ матриц; в) вычисление определенных интегралов; г) суммирование необходимого количества членов ряда для получения заданной точности. В качестве иллюстрации рассмотрены модельные примеры нагрева восьмислоевых конструкций в условиях пожара.
Научная новизна. Впервые прямой метод применен к решению задачи о распределении нестационарного температурного поля по толщине многослойных конструкций основных геометрических форм одновременно, при наличии неидеального теплового контакта между слоями.

Практическая значимость. Внедрение результатов исследования позволяет эффективно исследовать процессы теплообмена в многослойных конструкциях, которые встречаются в ряде прикладных задач.

Ключевые слова: теплообмен, коэффициент формы тела, неидеальный тепловой контакт

Recommended for publication by M. M. Semerak, Doctor of Technical Sciences. The manuscript was submitted 12.07.20. 